\title{
Factors Associated with Acid Fast Bacilli and Sputum Culture Conversion in Patients with Multidrug- Resistant Tuberculosis in Surabaya
}

\author{
Naomi Rahmasena ${ }^{1^{*}}$, Isnin Anang Marhana $^{(\mathbb{D}}$, Mohammad Yamin Sunaryo Suwandi $^{(\mathbb{D}}$, \\ Tutik Kusmiati $^{(i)}$, Tuksin Jearanaiwitayakul ${ }^{4}$
}

${ }^{1}$ Department of Psychiatry, Faculty of Medicine, Universitas Airlangga - Dr. Soetomo General Academic Hospital, Surabaya, Indonesia

${ }^{2}$ Departement of Pulmonology and Respiration, Faculty of Medicine, Univeristas Airlangga - Dr. Soetomo General Academic Hospital, Surabaya, Indonesia

${ }^{3}$ Departemen of Radiology, Faculty of Medicine, Univeristas Airlangga - Dr. Soetomo General Academic Hospital, Surabaya, Indonesia

${ }^{4}$ Department of Microbiology, Faculty of Science, Mahidol University, Bangkok, Thailand

\section{A R T I C L E I N F O}

\section{Article history:}

Received 9 September 2021

Received in revised form 4 October 2021

Accepted 19 October 2021

Available online 31 October 2021

\section{Keywords:}

Tuberculosis,

Multi-drug resistance,

Short-term regimen,

Sputum and culture conversion

*) Corresponding author:

izzatul-fithriyah@fk.unair.ac.id

\begin{abstract}
A B S T R A C T
Introduction: Indonesia is a high incidence country of multidrug-resistant tuberculosis. There are approximately 11,000 MDR TB cases, $2.8 \%$ of them are new cases and $16 \%$ of them are relapse cases. Although guidelines for MDR-TB are frequently designed, medication freely provided, and centers for treatment duly expanded, studies on time to sputum culture conversion have been very limited in Indonesia. Therefore the aim of the study is to identify risk factors that effect on sputum and culture conversion.

Methods: Data on short-term regimen for MDR TB in Dr. Soetomo General Hospital from January 1 st - December 31st, 2018 were collected with a total sampling approach, and fulfill the inclusion and exclusion. Data were analyzed by computer software IBM SPSS Statistic 24 for windows.

Result: Male is more likely to have delayed sputum conversion and culture conversion but no statistical difference is observed ( $p>0.05$ ). Smoking history is more likely to have delayed sputum and culture conversion but only in sputum smear test shows a significant difference $(p \leq 0.05)$. Alcohol consumption has delay effect on sputum and culture conversion but there is statistically difference in only culture conversion $(\mathrm{p}<0.05)$. The high baseline smear test also affects delay the sputum and culture conversion but only in sputum smear reveals a significant effect $(p<0.05)$. Conclusion: In this present study, we identified sex, smoking history, high bacillary loads as significant factors on sputum conversion. In addition, we revealed that alcohol-consumption history is a significant factor affecting on culture conversion.
\end{abstract}

\section{Introduction}

Tuberculosis is an infectious disease which is caused by Mycobacterium tuberculosis bacteria through inhalation of droplets contaminating bacteria. ${ }^{1}$ Risk factors contributing etiology of Tuberculosis are age, gender, immune status, malnutrition, diabetes, smoking, alcohol consumption, job, and poor ventilation. ${ }^{2}$ Rifampicin-resistance (RR TB), Multi-Drug Resistance (MDR TB), and Extensive Drug Resistance (XDR TB) are currently the most prevalence of drug resistant bacteria found in the TB patients. ${ }^{3}$ MDR TB is defined by resistance to the first two lines of treatment namely isoniazid and rifampicin. ${ }^{4}$

According to the data from the WHO (World Health Organization) in 2017 , there are $4.1 \%$ of patient with MDR tuberculosis and $19 \%$ of them are relapse cases 3 . Meanwhile, there are approximately 32,000 MDR TB cases reported on 2017 in Indonesia. Among of MDR TB patients, $2.8 \%$ of them are new cases and $16 \%$ of 
them are relapse cases. An increase in MDR TB cases raises anxiety to the national public health, while the policy of the Sustainable Development Goals is that the free from tuberculosis, AIDS, malaria, and neglected tropical disease in $2030 .^{3}$

In May 2016, WHO recommended a regiment with duration of nine to twelve months. This regiment is applied to more than $85 \%$ of multidrug-resistant tuberculosis patients5. The advantages of this treatment are shorter time, lower prices, and easier for drug management. ${ }^{6}$

As stated by the Indonesian Minister of Health Regulations 364/MENKSE/SK/V/2009, TB diagnoses are carried out by culture examination (gold standard). While culture examination takes longer time, a direct microscopic sputum specimen examination is preferred. ${ }^{7}$ WHO stated that the failure of therapy was determined if the results of culture and AFB remained positive until the end of the intensive phase. There was a reversion, when resistance of fluoroquinolone or the second line of the anti-tuberculosis drug, and even the adverse drug reactions emerged. Therefore, this present study aims to investigate the contributing factors of the patient's initial status that impact on the duration of sputum conversion and sputum culture. ${ }^{8}$

\section{Methods}

This research is an observational analytic study that aims to find out the tuberculosis factors that affect AFB sputum conversion and culture conversion. The definition of conversion is conversion from positive result to negative result. The data used is secondary data from medical record of patient in General Hospital Dr. Soetomo Surabaya period January 1st, 2018 until December 31st, 2018 at the multidrugresistant pulmonary tuberculosis polyclinic. The sample of this research is all the medical records of MDR TB patients that fulfilled the inclusion criteria including completed medical record, above 18 years old, presence of diabetes mellitus, patients who routinely come to see the doctor for 6 months with short-term regimens. The exclusion criteria used were complications other than diabetes mellitus. The sample was collected by total sampling. The total number of the patients at the MDR TB polyclinic in 2018 were 150 patients, then narrowed to short-term therapy to 88 patients, with inclusion and exclusion criteria narrowed down again to 32 patients. Data were Analyzed using contingency table that generates odds ratio by a computer software program IBM SPSS Statistics 24 for windows with significance level $(\alpha)$ 0,05 .

\section{Results}

The research results showed that of the 32 patients who met the inclusion criteria, there were 23 male and 9 female patients. A total of 17 patients had a smoking history and 6 patients had an alcohol history. This research also found that 8 patients had comorbid diabetes mellitus. Based on the AFB baseline test, 5 patients were negative, there were no patients with scanty, 7 patients had AFB baseline test $1+, 10$ patients had AFB baseline test $2+$, and 10 patients had AFB baseline test $3+$ (Table 1).
Table 1. Profile, Results of Sputum and Culture Conversion of Patients at MDR TB polyclinic RSUD Dr. Soetomo during January - December 2018.

In the acid-fast bacilli staining method, it was found that more males had sputum conversion. Males were more likely to experience 3.89 conversions in the second month compared to the first month $(p=0.78)$ and tended to experience 2.143 conversions in the third month compared to the second month $(p=0.175)$. With the culture method, males become a protective factor in the second month compared to the first month $(p=0.245)$ and experience 1.7 times of conversion in the third month compared to the second $(p=0.2)$ (Table 2 and 3 ).

Patients with smoking history tended to be risk factors in the sputum conversion. Patients with smoking history were more likely to experience 1.091 conversions in the second month compared to the first month $(p=0.46)$, tend to experience 7 conversions in the third month compared to the second $(p=0.05)$. Significantly, we found that 7.609 times more conversion of patient with smoking history in the third month than the first month $(p=0.03)$ compared to patients without a history of previous smoking. Using culture method, patients experienced 1.71 times conversion longer during the second month compared to the first month $(p=0.246), 2.625$ conversions longer in the third month compared to the first month $(p=0.148)$, and have 3.8 times more sputum conversion in the third month than the first month $(p=0.1)$ compared to patients without a previous smoking history.

Patients with alcohol history tended to experience longer conversion than patients without alcohol history. In the acid-fast bacilli staining method, it was found that patients with alcohol history were more likely to experience 2.5 times of conversion in the third month compared to the second month $(\mathrm{p}=0.33)$, and experience 2.375 times of conversion in the third month than the first month $(p=0.286)$ compared to patients without alcohol history. In the culture method, it was found that patients with alcohol history tended to experience 27 times more conversions in the third month than in the second month $(p=0.01)$, and experience 3 times more conversions in the third month than the first month $(p=0.13)$ compared to patients without alcohol history (table 2 and 3 ).

In the acid-fast bacilli staining method, the results of sputum conversion using acid-fast bacilli were compared between groups. The groups compared were shown as follows: AFB $1+$ vs AFB negative, AFB 2+ vs AFB negative, AFB $3+$ vs AFB negative, $\mathrm{AFB} 2+\mathrm{vs} \mathrm{AFB} 1+$, AFB $3+\mathrm{vs} \mathrm{AFB}+1$, and AFB 3+ vs AFB $2+$.

In general, patients who come to MDR TB clinic have a relatively high AFB baseline of $2+$ or $3+$. Using the AFB test, the AFB 3+ group had a significantly correlated with sputum conversion that was longer than the other AFB grading. The results of the culture test did not indicate a significant relationship in the duration of sputum conversion (table 2 and 3 ). 
Table 1. Profile, Results of Sputum and Culture Conversion of Patients at MDR TB polyclinic RSUD Dr. Soetomo during January - December 2018

\begin{tabular}{lcccccccc}
\hline Predictor & Amount & Percentage & \multicolumn{2}{c}{ Months of AFB Conversion } & \multicolumn{3}{c}{ Months of Culture Conversion } \\
& $(\mathbf{n}=\mathbf{3 2})$ & $\mathbf{( \% )}$ & $\mathbf{1}$ & $\mathbf{2}$ & $\mathbf{3}$ & $\mathbf{1}$ & $\mathbf{2}$ & $>\mathbf{3}$ \\
\hline Gender & & & & & & & & \\
\hline Male & 23 & 71.875 & 9 & 10 & 4 & 13 & 9 & 1 \\
\hline Female & 9 & 28.125 & 7 & 2 & 0 & 4 & 5 & 0 \\
\hline Smoking History & & & & & & & & \\
\hline Yes & 17 & 53.125 & 11 & 3 & 3 & 7 & 8 & 1 \\
\hline No & 15 & 46.875 & 12 & 3 & 0 & 9 & 6 & 0 \\
\hline Alcohol History & & & & & & & & \\
\hline Yes & 6 & 18.75 & 4 & 1 & 1 & 4 & 1 & 1 \\
\hline No & 26 & 81.25 & 19 & 5 & 2 & 13 & 13 & 0 \\
\hline Narcotic & 0 & 0 & 0 & 0 & 0 & 0 & 0 & 0 \\
\hline Comorbid & & & & & & & & \\
\hline Diabetes Mellitus & 8 & 25 & 7 & 1 & 0 & 4 & 4 & 0 \\
\hline No & 24 & 75 & 15 & 6 & 3 & 13 & 10 & 1 \\
\hline AFB Baseline & & & & & & & & \\
\hline Negative & 5 & 15.625 & 5 & 0 & 0 & 1 & 4 & 0 \\
\hline BTA 1+ & 7 & 21.875 & 4 & 2 & 1 & 2 & 5 & 0 \\
\hline BTA 2+ & 10 & 31.25 & 6 & 3 & 1 & 6 & 4 & 0 \\
\hline BTA 3+ & 10 & 31.25 & 8 & 1 & 10 & 4 & 5 & 1 \\
\hline
\end{tabular}

Table 2. Data Analysis Results Using Acid Fast Bacilli Test (AFB)

\begin{tabular}{|c|c|c|c|c|c|c|c|c|c|c|c|c|}
\hline \multirow[t]{2}{*}{ Predictor } & \multicolumn{2}{|c|}{$\begin{array}{l}\text { Months of } \\
\text { Conversion }\end{array}$} & \multirow[t]{2}{*}{ OR } & \multirow[t]{2}{*}{ P value } & \multicolumn{2}{|c|}{$\begin{array}{c}\text { Months of } \\
\text { Conversion }\end{array}$} & \multirow[t]{2}{*}{ OR } & \multirow[t]{2}{*}{$P$ value } & \multicolumn{2}{|c|}{$\begin{array}{l}\text { Months of } \\
\text { Conversion }\end{array}$} & \multirow[t]{2}{*}{ OR } & \multirow[t]{2}{*}{$P$ value } \\
\hline & 3 & 2 & & & 2 & 1 & & & 3 & 1 & & \\
\hline \multicolumn{13}{|l|}{ Gender } \\
\hline Male & 4 & 10 & \multirow{2}{*}{2.143} & \multirow{2}{*}{0.175} & 10 & 9 & \multirow{2}{*}{0.32} & \multirow{2}{*}{0.1197} & 4 & 9 & \multirow{2}{*}{7.105} & \multirow{2}{*}{0.08} \\
\hline Female & 0 & 2 & & & 7 & 2 & & & 0 & 7 & & \\
\hline \multicolumn{13}{|c|}{ Smoking History } \\
\hline Yes & 3 & 3 & \multirow[b]{2}{*}{7} & \multirow[b]{2}{*}{0,05} & 3 & 11 & \multirow[b]{2}{*}{1,09} & \multirow[b]{2}{*}{0,46} & 3 & 11 & \multirow[b]{2}{*}{7.609} & \multirow[b]{2}{*}{$0.03^{*}$} \\
\hline No & 0 & 3 & & & 3 & 12 & & & 0 & 12 & & \\
\hline
\end{tabular}

\begin{tabular}{|c|c|c|c|c|c|c|c|c|c|c|c|c|}
\hline \multicolumn{13}{|c|}{ Alcohol Consumption } \\
\hline Yes & 1 & 1 & \multirow{2}{*}{2.5} & \multirow{2}{*}{0.33} & 1 & 4 & \multirow{2}{*}{0.95} & \multirow{2}{*}{0.49} & 1 & 4 & \multirow{2}{*}{2.375} & \multirow{2}{*}{0.286} \\
\hline No & 2 & 5 & & & 5 & 19 & & & 2 & 19 & & \\
\hline \multicolumn{13}{|l|}{ Diabetes } \\
\hline Yes & 0 & 1 & \multirow{2}{*}{0.619} & \multirow{2}{*}{0.33} & 1 & 7 & 0,36 & 0,2136 & 0 & 7 & \multirow{2}{*}{0.2952} & \multirow{2}{*}{0.2136} \\
\hline No & 3 & 6 & & & 6 & 15 & & & 3 & 15 & & \\
\hline \multicolumn{13}{|c|}{ AFB Baseline } \\
\hline BTA 1+ & 1 & 2 & & & 2 & 4 & \multirow{2}{*}{0.16} & \multirow{2}{*}{0.342} & 1 & 4 & \multirow{2}{*}{0.27} & \multirow{2}{*}{0.5} \\
\hline Negative & 0 & 0 & & & 0 & 5 & & & 0 & 5 & & \\
\hline BTA 2+ & 1 & 3 & & & 3 & 6 & \multirow{2}{*}{5.29} & \multirow{2}{*}{0.057} & 1 & 6 & \multirow{2}{*}{2.53} & \multirow{2}{*}{0.15} \\
\hline Negative & 0 & 0 & & & 0 & 5 & & & 0 & 5 & & \\
\hline BTA 3+ & 10 & 1 & & & 1 & 8 & \multirow{2}{*}{1.94} & \multirow{2}{*}{0.187} & 10 & 8 & \multirow{2}{*}{12.35} & \multirow{2}{*}{$0.0389^{*}$} \\
\hline Negative & 0 & 0 & & & 0 & 5 & & & 0 & 5 & & \\
\hline BTA 2+ & 1 & 3 & \multirow{2}{*}{0.295} & \multirow{2}{*}{0.441} & 3 & 6 & \multirow{2}{*}{1} & \multirow{2}{*}{0.496} & 1 & 6 & \multirow{2}{*}{0.41} & \multirow{2}{*}{0.428} \\
\hline BTA 1+ & 1 & 2 & & & 2 & 4 & & & 1 & 4 & & \\
\hline
\end{tabular}




\begin{tabular}{|c|c|c|c|c|c|c|c|c|c|c|c|c|}
\hline BTA 3+ & 10 & 1 & 20 & $004 *$ & 1 & 8 & 0667 & 01286 & 10 & 8 & 5 & 01 \\
\hline BTA $1+$ & 1 & 2 & 20 & 0.04 & 2 & 4 & 0.007 & 0.4200 & 1 & 4 & 3 & 0.1 \\
\hline BTA 3+ & 10 & 1 & \multirow{2}{*}{30} & \multirow{2}{*}{$0.01 *$} & 1 & 8 & 0,25 & 0,192 & 10 & 8 & \multirow{2}{*}{7.5} & \multirow{2}{*}{$0.04 *$} \\
\hline BTA 2+ & 1 & 3 & & & 3 & 6 & & & 1 & 6 & & \\
\hline
\end{tabular}

$\mathrm{p}<0.05$

Table 3. Analysis Results Using Culture Test

\begin{tabular}{|c|c|c|c|c|c|c|c|c|c|c|c|c|}
\hline \multirow[t]{2}{*}{ Predictor } & \multicolumn{2}{|c|}{$\begin{array}{l}\text { Months of } \\
\text { Conversion }\end{array}$} & \multirow[t]{2}{*}{ OR } & \multirow[t]{2}{*}{ P value } & \multicolumn{2}{|c|}{$\begin{array}{l}\text { Months of } \\
\text { Conversion }\end{array}$} & \multirow[t]{2}{*}{ OR } & \multirow[t]{2}{*}{$P$ value } & \multicolumn{2}{|c|}{$\begin{array}{c}\text { Months of } \\
\text { Conversion }\end{array}$} & \multirow[t]{2}{*}{ OR } & \multirow[t]{2}{*}{$P$ value } \\
\hline & 3 & 2 & & & 2 & 1 & & & 3 & 1 & & \\
\hline \multicolumn{13}{|l|}{ Gender } \\
\hline Male & 1 & 9 & \multirow{2}{*}{1.7} & \multirow{2}{*}{0.2} & 9 & 13 & \multirow{2}{*}{0.5647} & \multirow{2}{*}{0.2452} & 1 & 13 & \multirow{2}{*}{1} & \multirow{2}{*}{0.2763} \\
\hline Female & 0 & 5 & & & 5 & 4 & & & 0 & 4 & & \\
\hline \multicolumn{13}{|c|}{ Smoking History } \\
\hline Yes & 1 & 8 & \multirow[b]{2}{*}{2.625} & \multirow[b]{2}{*}{0.148} & 8 & 7 & \multirow[b]{2}{*}{1.71} & \multirow[b]{2}{*}{0.246} & 1 & 7 & \multirow[b]{2}{*}{3.8} & \multirow[b]{2}{*}{0.1} \\
\hline No & 0 & 6 & & & 6 & 9 & & & 0 & 9 & & \\
\hline \multicolumn{13}{|c|}{ Alcohol Consumption } \\
\hline Yes & 1 & 1 & \multirow{2}{*}{27} & \multirow{2}{*}{$0.01 *$} & 1 & 4 & \multirow{2}{*}{0.26} & \multirow{2}{*}{0.1345} & 1 & 4 & 3 & 0130 \\
\hline No & 0 & 13 & & & 13 & 13 & & & 0 & 13 & 3 & 0.139 \\
\hline Diabetes & & & & & & & & & & & & \\
\hline Yes & 0 & 4 & 560 & 0 & 4 & 4 & 1.3 & 0.3831 & 0 & 4 & 1 & 025 \\
\hline No & 1 & 10 & 2.509 & 0.29 & 10 & 13 & & & 1 & 13 & 1 & 0.25 \\
\hline AFB Baseli & & & & & & & & & & & & \\
\hline BTA $1+$ & 0 & 5 & & & 5 & 2 & 1 & 0307 & 0 & 2 & & \\
\hline Negative & 0 & 4 & & & 4 & 1 & 1.0 & ו וב. & 0 & 1 & & \\
\hline BTA 2+ & 0 & 4 & & & 4 & 6 & 0167 & 01 & 0 & 6 & & \\
\hline Negative & 0 & 4 & & & 4 & 1 & 0.107 & 0.1 & 0 & 1 & & \\
\hline BTA 3+ & 1 & 5 & 215 & 016 & 5 & 4 & 03125 & 022 & 1 & 4 & 1 & 02670 \\
\hline Negative & 0 & 4 & 2.45 & 0.10 & 4 & 1 & 0.3125 & 0.22 & 0 & 1 & 1 & 0.2019 \\
\hline BTA 2+ & 0 & 4 & & & 4 & 6 & 0267 & 0127 & 0 & 6 & 08452 & 04615 \\
\hline BTA $1+$ & 0 & 5 & & & 5 & 2 & $0.20 /$ & 0.121 & 1 & 4 & 0.8452 & 04015 \\
\hline BTA 3+ & 1 & 5 & 3 & 01346 & 5 & 4 & 0.5 & 02858 & 1 & 4 & 167 & 0208 \\
\hline BTA 1+ & 0 & 5 & & & 5 & 2 & & & 0 & 2 & 1.07 & \\
\hline BTA 3+ & 1 & 5 & 245 & 0159 & 5 & 4 & 1.875 & 0.27 & 1 & 4 & 43 & 009 \\
\hline BTA 2+ & 0 & 4 & 2.45 & & 4 & 6 & & & 0 & 6 & & \\
\hline
\end{tabular}

\section{Discussion}

The results of this study show that there is no significant relationship between gender and AFB conversion or culture. Males prone to have sputum conversion longer than females based on the acid-fast bacilli method, whereas in the culture method there is no significant relationship. ${ }^{9}$

Research results show that patients who did not have a history of smoking tended to experience sputum conversion faster than patients with smoking history. However, no significant correlation was found in the smoking group with culture conversion. Nevertheless, these results are likely to be significant if longer studies are carried out as suggested by research conducted by Merge et al. ${ }^{10}$

Smoking is one of the risk factors that affects disease outcome through systemically and respiratory system in both children and adults such as pneumonia, influenza, fever, and tuberculosis. ${ }^{11}$ Gas and harmful particles that are found in cigarettes can lead to alteration of immune system, resulting in cellular chronic inflammation. Chronic inflammation can cause pathological changes such as chronic obstructive bronchitis with fibrosis, obstruction of the respiratory tract, emphysema with enlarged air space, destruction of the lung parenchyma, and loss of lung elasticity. ${ }^{12,13}$ Inhaled particles will be stored in the respiratory tract depending on the particle size. The large particles will be trapped in the upper respiratory tract, whereas small particles will be easy to penetrate to the alveoli. Particles that are difficult to remove are accumulated in respiratory tissues, thus causing chronic inflammation. ${ }^{14}$ Smoking can reduce the mucociliary function by decreasing the frequency of ciliary epithelial layer, and increasing goblet cells, submucosal gland 
hypertrophy and squamous cell metaplasia. ${ }^{15}$ Smoking activates respiratory endothelium to produce inflammatory cytokines and chemokines such as tumor necrosis factor (TNF)- $\alpha$ interleukin (IL)- $1 \beta$, granulocyte-macrophage colony-stimulating factor, IL-8, dan Leukotriene (LT). These immune mediators are responsible for activating and recruiting alveolar macrophage and neutrophils. ${ }^{13}$ Cigarette consumption can cause the suppression of neutrophil caspase-3-like activity, which in turn, interfere the phagocyte activity. Cigarette can also reduce the function alveolar macrophage activity and phagocytic neutrophils. This affects to adaptive immunity, resulting in decreasing serum immunoglobulin (IgA and $\operatorname{IgM}$ ) levels and natural killer (NK) cells. ${ }^{16,17,18}$ Passive smokers who inhale cigarette smoke can result in decrease in production of interferon IFN- $\gamma$. Typically IFN- $\gamma$ is the main cytokine involving in protective immunity against intracellular pathogens. Reduction of IFN- $\gamma$ responses associates with diminishing T cell response to Mycobacterium tuberculosis DNA vaccine, and disrupting $\mathrm{T}$ cell immunity against Mycobacterium tuberculosis. Also, cigarette smoke can inhibit the production of CD4 T cells, which is crucial for host defense against Mycobacterium tuberculosis, and influenza. ${ }^{12}$ In addition, IFN- $\gamma$ is the main key mediator for combating tuberculosis. Mice deficient in IFN- $\gamma$ production are found to be more susceptible to Mycobacterium tuberculosis. ${ }^{19}$

Our study revealed that patients with a history of alcohol tended to experience sputum conversion longer than patients without a history of alcohol consumption. Patients with alcohol consumption are likely to have more disease severity and higher risk of mortality caused by tuberculosis when they first enter the hospital. ${ }^{20}$ Our results are in agreement with previous studies. ${ }^{21,22}$ It is revealed that ethanol has an inhibitory effect on tolllike receptors (TLRs) signaling, resulting in a decreased cytokine production such as TNF- $\alpha$, IL-1, and IL-6. ${ }^{23,24}$ Alcohol consumption causes loss in the lung defenses. This will increase susceptibility of infections at lung organ.25 Migration inhibition factor (MIF) is soluble immune cytokine produced by $\mathrm{T}$ cells, macrophages and other phagocytes in the area of infection. Animals consumed alcohol showed that production of migration inhibition factor (MIF) production was inhibited. ${ }^{26}$ Individuals with latent tuberculosis infection with excessive alcohol consumption are supposed to have weakened immune system. ${ }^{27}$ Alveolar macrophage in rats with chronic alcohol consumption shows a decrease in the expression of granulocyte-macrophage colony-stimulating factor (GM-CSF) receptor and interfere the phagocytic activity. ${ }^{28}$ Furthermore alcohol induces oxidative stress in alveolar macrophages by upregulating an expression of nicotineamide adenine dinucleotide phosphate (NADPH) oxidase family NADPH oxidase 1 (NOX1), NADPH oxidase 2 (NOX2), and NADPH oxidase 4 (NOX4) found in animals and humans that participated in the study of alcoholism. ${ }^{29}$ In one study, the return of glutathione supplies through its precursors, $\mathrm{N}$-acetylcysteine in the alveolar ameliorate the function of alveolar phagocyte and reduce alveolar tissue damage in experimental animals. ${ }^{30}$ Other than that, alcohol also increases leukocyte cells (for example neutrophils) in alveolar, interferes with the function of neutrophils in response to infections, and reduces protein activity that affects the immune response. ${ }^{31} \mathrm{NK}$ cells are also found to be decreased and abnormal in mice with alcohol consumption. ${ }^{32} \mathrm{NK}$ cell production in the bone marrow is also disrupted due to the decreased production of the lien and an increase in the percentage of NK cells produced by thymus, NK cells produced in thymus have the low cytolytic capacity but increase cytokine production.

From our study, it revealed that AFB smear test baseline results have a significant relationship with AFB sputum conversion. This result is supported by where high sputum baseline (3+) affects the duration AFB conversion, but does not affect culture conversion. ${ }^{10}$

Therefore from this study revealed that gender, cigarettes, and AFB smear test baseline influence the duration of AFB conversion, meanwhile history of alcohol consumption also influence the duration of culture conversion. As a consequence, we need to educate and influence the patient to control their lifestyle also the family member just in case of prevention as they are close contact of the patient. However retrospective retrieval study revealed inconsistencies of results between culture and sputum conversion.

\section{Conclusion}

In this study, the factors that influence the duration of sputum conversion with acid-fast bacilli staining method were gender, cigarettes, high sputum baseline. However, the culture method that significantly influences is alcohol history.

Further research will be conducted using the perspective cohort method where research can be performed from the beginning to the end of treatment to determine the success of the therapy.

\section{Conflict of Interest}

The authors declare that there is no conflict of interest.

\section{References}

1. Departemen Kesehatan. Tuberkulosis (Tb). , Http://www.depkes.go.id/ development/site/depkes/pdf.Php?Id=1-17042500005 (2017, Accessed April 2, 2018).

2. Narasimhan P, Wood J, Macintyre Cr, Et Al. Risk Factors For Tuberculosis. Pulmonary Medicine; 2013. Epub Ahead Of Print 2013. DOI: $10.1155 / 2013 / 828939$.

3. World Health Organization. Global Tuberculosis Report, Https:// Www.Who.Int/Tb/Areas-Of-Work/Drug-Resistant-Tb/Mdr_Tb_2017. Pdf?Ua=1 (2017, Accessed September 15, 2019).

4. Ormerod Lp. Multidrug-Resistant Tuberculosis (Mdr-Tb): Epidemiology, Prevention And Treatment. British Medical Bulletin; 73-74. Epub Ahead Of Print January 1, 2005. Doi: 10.1093/Bmb/Ldh047.

5. Van Deun A, Maug Akj, Salim Mah, Et Al. Short, Highly Effective, And Inexpensive Standardized Treatment Of Multidrug-Resistant Tuberculosis. American Journal Of Respiratory And Critical Care Medicine; 182. Epub Ahead Of Print September 2010. Doi: 10.1164/ Rccm.201001-0077oc.

6. Treatment Action Group. Is Shorter Better? Understanding The Shorter Regimen For Treating Drug-Resistant Tuberculosis, Http:/Www. Treatmentactiongroup.Org/Content/Is-Shorter-Better (2019, Accessed September 15, 2017).

7. Kementerian Kesehatan Republik Indonesia. Keputusan Menteri Kesehatan Republik Indonesia Nomor 364/Menkes/Sk/V/2009 Tentang Pedoman Penanggulangan Tuberkulosis (Tb). Jakarta, Https:/Www. Persi.Or.Id/Images/Regulasi/Kepmenkes/Kmk3642009.Pdf $\quad$ (2014, Accessed June 11, 2019).

8. World Health Organization. Definitions And Reporting Framework For Tuberculosis- 2013 Revision

9. Güler M, Ünsal E, Dursun B, Et Al. Factors Influencing Sputum Smear And Culture Conversion Time Among Patients With New Case Pulmonary Tuberculosis. International Journal Of Clinical Practice; 61. Epub Ahead Of Print December 6, 2006. Doi: 10.1111/J.1742-1241.2006.01131.X. 
10. Magee Mj, Foote M, Maggio Dm, Et Al. Diabetes Mellitus And Risk Of All-Cause Mortality Among Patients With Tuberculosis In The State Of Georgia, 2009-2012. Annals Of Epidemiology; 24. Epub Ahead Of Print May 2014. Doi: 10.1016/J.Annepidem.2014.01.012.

11. Arcavi L, Benowitz Nl. Cigarette Smoking And Infection. Archives Of Internal Medicine; 164. Epub Ahead Of Print November 8, 2004. Doi: 10.1001/Archinte.164.20.2206.

12. Barnes Pj. Mediators Of Chronic Obstructive Pulmonary Disease. Pharmacological Reviews; 56. Epub Ahead Of Print December 2004. Doi: $10.1124 / \operatorname{Pr} .56 .4 .2$.

13. Cosio Mg, Saetta M, Agusti A. Immunologic Aspects Of Chronic Obstructive Pulmonary Disease. New England Journal Of Medicine; 360. Epub Ahead Of Print June 4, 2009. Doi: 10.1056/Nejmra0804752.

14. Ling S. Particulate Matter Air Pollution Exposure: Role In The Development And Exacerbation Of Chronic Obstructive Pulmonary Disease. International Journal Of Chronic Obstructive Pulmonary Disease. Epub Ahead Of Print June 2009. Doi: 10.2147/Copd.S5098.

15. Mehta H, Nazzal K, Sadikot Rt. Cigarette Smoking And Innate Immunity. Inflammation Research; 57. Epub Ahead Of Print November 13, 2008. Doi: 10.1007/S00011-008-8078-6.

16. Stringer Ka, Tobias M, O'neill Hc, Et Al. Cigarette Smoke ExtractInduced Suppression Of Caspase-3-Like Activity Impairs Human Neutrophil Phagocytosis. American Journal Of Physiology-Lung Cellular And Molecular Physiology; 292. Epub Ahead Of Print June 2007. Doi: 10.1152/Ajplung.00325.2006.

17. Berenson Cs, Garlipp Ma, Grove Lj, Et Al. Impaired Phagocytosis Of Nontypeable Haemophilus Influenzae By Human Alveolar Macrophages In Chronic Obstructive Pulmonary Disease. The Journal Of Infectious Diseases; 194. Epub Ahead Of Print November 15, 2006. Doi: 10.1086/508428.

18. Berenson Cs, Garlipp Ma, Grove Lj, Et Al. Impaired Phagocytosis Of Nontypeable Haemophilus Influenzae By Human Alveolar Macrophages In Chronic Obstructive Pulmonary Disease. The Journal Of Infectious Diseases; 194. Epub Ahead Of Print November 15, 2006. Doi: $10.1086 / 508428$.

19. Cooper Am, Dalton Dk, Stewart Ta, Et Al. Disseminated Tuberculosis In Interferon Gamma Gene-Disrupted Mice. Journal Of Experimental Medicine; 178. Epub Ahead Of Print December 1, 1993. Doi: 10.1084/ Jem.178.6.2243.

20. Bermudez Le, Wu M, Martinelli J, Et Al. Ethanol Affects Release Of Tnf And Gm-Csf And Membrane Expression Of Tnf Receptors By Human Macrophages. Lymphokine And Cytokine Research; 10.

21. Yihunie Akalu T, Muchie Kf, Alemu Gelaye K. Time To Sputum Culture Conversion And Its Determinants Among Multi-Drug Resistant Tuberculosis Patients At Public Hospitals Of The Amhara Regional State: A Multicenter Retrospective Follow Up Study. Plos One; 13. Epub Ahead Of Print June 21, 2018. Doi: 10.1371/Journal.Pone.0199320.

22. Gelmanova Iy, Keshavjee S, Golubchikova Vt, Et Al. Barriers To Successful Tuberculosis Treatment In Tomsk, Russian Federation: NonAdherence, Default And The Acquisition Of Multidrug Resistance. Bulletin Of The World Health Organization 2007; 85: 703-711.
23. Deviere J, Content J, Denys C, Et Al. High Interleukin-6 Serum Levels And Increased Production By Leucocytes In Alcoholic Liver Cirrhosis. Correlation With Iga Serum Levels And Lymphokines Production. Clinical And Experimental Immunology; 77.

24. Gamble L, Mason Cm, Nelson S. The Effects Of Alcohol On Immunity And Bacterial Infection In The Lung. Médecine Et Maladies Infectieuses; 36. Epub Ahead Of Print February 2006. Doi: 10.1016/J. Medmal.2005.08.010.

25. Simet Sm, Sisson Jh. Alcohol's Effects On Lung Health And Immunity. Alcohol Research : Current Reviews; 37.

26. Gambo'Ngambo' Gambo'N-Deza F, Carracedo Mp, Cerda'Mota T, Et Al. Lymphocyte Populations During Tuberculosis Infection: V Repertoires. 1995.

27. Roselle Ga, Mendenhall Cl, Grossman Cj. Age Dependent Alterations Of Host Immune Response In The Ethanol-Fed Rat. Journal Of Clinical \& Laboratory Immunology; 29.

28. Joshi Pc, Applewhite L, Ritzenthaler Jd, Et Al. Chronic Ethanol Ingestion In Rats Decreases Granulocyte-Macrophage Colony-Stimulating Factor Receptor Expression And Downstream Signaling In The Alveolar Macrophage. The Journal Of Immunology; 175. Epub Ahead Of Print November 15, 2005. Doi: 10.4049/Jimmunol.175.10.6837.

29. Yeligar Sm, Harris Fl, Hart Cm, Et Al. Ethanol Induces Oxidative Stress In Alveolar Macrophages Via Upregulation Of Nadph Oxidases. The Journal Of Immunology; 188. Epub Ahead Of Print April 15, 2012. Doi: 10.4049/Jimmunol.1101278.

30. Yeligar Sm, Harris Fl, Hart Cm, Et Al. Glutathione Attenuates EthanolInduced Alveolar Macrophage Oxidative Stress And Dysfunction By Downregulating Nadph Oxidases. American Journal Of Physiology-Lung Cellular And Molecular Physiology; 306. Epub Ahead Of Print March 1, 2014. Doi: 10.1152/Ajplung.00159.2013.

31. Boé Dm, Nelson S, Zhang P, Et Al. Acute Ethanol Intoxication Suppresses Lung Chemokine Production Following Infection With Streptococcus Pneumoniae. The Journal Of Infectious Diseases; 184. Epub Ahead Of Print November 2001. Doi: 10.1086/323661.

32. Blank Se, Pfister Lj, Gallucci Rm, Et Al. Ethanol-Induced Changes In Peripheral Blood And Splenic Natural Killer Cells. Alcoholism: Clinical And Experimental Research; 17. Epub Ahead Of Print June 1993. Doi: 10.1111/J.1530-0277.1993.Tb00800.X.

33. Zhang H, Meadows Gg. Chronic Alcohol Consumption Perturbs The Balance Between Thymus-Derived And Bone Marrow-Derived Natural Killer Cells In The Spleen. Journal Of Leukocyte Biology; 83. Epub Ahead Of Print January 2008. Doi: 10.1189/Jlb.0707472.

34. Arase H. Direct Recognition Of Cytomegalovirus By Activating And Inhibitory Nk Cell Receptors. Science; 296. Epub Ahead Of Print May 17, 2002. Doi: $10.1126 /$ Science. 1070884.

35. Dorio Rj. The Effect Of Ethanol On Signal Transduction In The Rat Alveolar Macrophage. Progress In Clinical And Biological Research; 325. 